\title{
Resilience and household food security: a review of concepts, methodological approaches and empirical evidence
}

\author{
Isaac Gershon Kodwo Ansah ${ }^{1,2}$ (D) $\cdot$ Cornelis Gardebroek ${ }^{3} \cdot$ Rico Ihle $^{3}$
}

Received: 20 June 2018 / Accepted: 13 August 2019 / Published online: 28 August 2019

(C) The Author(s) 2019

\begin{abstract}
The way economic studies conceptualize and measure resilience is very heterogeneous. This does not only challenge scientific progress, but also raises the question of whether they measure one identical concept with different methods or whether they measure different understandings of resilience. This paper provides a review of concepts, methodological approaches and empirical evidence on resilience from a food security perspective, focusing on socioeconomic research. We perform a systematic literature search to identify recent publications that analyze resilience from the perspective of household food security. We examine the historical evolution of concepts and methods used for measuring resilience and synthesize the evidence. We find that conceptual and analytical models have evolved over time, with important technical adjustments. Studies initially focused on measuring resilience as an end in itself, but more recently resilience is understood as a means to an ultimate end, hence resilience capacity is measured instead. Also, resilience was initially measured as an indicator of food security. Currently it is measured distinctly from food security. Multivariate techniques are found to be frequently used to quantify resilience. The empirical evidence suggests that households with higher resilience capacity tend to have less child malnutrition and better food security. We find that causal pathways through which resilience capacity affects food security in a microeconomic framework are barely explicitly considered in empirical analyses. Therefore, we suggest a model which explicitly addresses these pathways.
\end{abstract}

Keywords Resilience $\cdot$ Food security $\cdot$ Households $\cdot$ Measurement

JEL classification Q10 · Q12 · Q50

Isaac Gershon Kodwo Ansah

agershon@uds.edu.gh

Cornelis Gardebroek

koos.gardebroek@wur.nl

Rico Ihle

rico.ihle@wur.nl

1 Department of Agricultural and Resource Economics, Faculty of Agribusiness and Communication Sciences, University for Development Studies, P.O Box TL, 1882 Tamale, Ghana

2 Agricultural Economics and Rural Policy Group, Department of Social Sciences, Wageningen University and Research, Hollandseweg 1, 6706, KN Wageningen, The Netherlands

\section{Introduction}

Farm households in developing countries often face a wide range of recurring and unanticipated environmental, ecological, or socio-economic shocks. The welfare costs of such shocks are often significant and draw policy and humanitarian attention. After Holling (1973)'s influential paper on resilience, this concept has been adopted by many development actors to better understand the robustness of food systems and their ability to adapt in the wake of shocks (Pingali et al. 2005; Constas et al. 2014a; Constas et al. 2016). Besides, understanding resilience in household food systems may help in better programming of interventions that affect food systems in shock-prone developing regions (Thompson and Scoones 2009; Fan et al. 2014; OECD 
2013; UNDP 2012). Furthermore, recent discourses in media and policy have been arguing that resilience in food systems could be a panacea for food security in developing countries (EU 2012).

Resilience has been defined from a social-ecological perspective as the capacity of socioeconomic systems (e.g., households) to withstand shocks through absorption, adaptation and transformation (Walker et al. 2004; Folke 2006; Gunderson 2000). Resilience has been applied in various contexts to understand whether and how social and economic systems could become more robust to shocks (Barrett and Constas 2014; Doran and Fingleton 2016; Folke 2006; Martin and Sunley 2014). However, for the specific application of resilience to food systems only few conceptual studies have emerged and these tend to treat the topic from a general perspective (Toth et al. 2016; Pingali et al. 2005; Tendall et al. 2015). What remains a challenge is how to operationalize resilience in a household food systems context in order to assess it empirically. Further, due to the complex nature of the resilience concept, various studies tend to propose different theories and methods that often generate different results. Empirical studies published in recent years diverge on the operationalization and methodological measurement of resilience, thus yielding outcomes which are hardly comparable. Such heterogeneity challenges scientific progress and does little help to properly inform policy and investment decisions (Serfilippi and Ramnath 2018). The heterogeneous results also raise the question of whether these studies measure the same concept with different methods or measure different things and refer to it as resilience. Therefore, a synthesis of studies that address resilience from a food security perspective is important and can help focus research by building on existing best practices.

The objective of this paper is to review the resilience literature from a food security perspective and to identify and synthesize concepts, methodological approaches and relationships that exist between resilience and food security. First, we provide an overview of the developments of conceptual and analytical frameworks guiding the resilience-food security discourse. Second, we examine the empirical evidence of the relation between resilience and food security. Third, we assess whether the studies identified indeed operationalize and measure the relationship between resilience and food security. Serfilippi and Ramnath (2018) provide a literature review of the research on resilience in general as applied by humanitarian organizations. Our paper extends their work in two main respects. First, we focus specifically on the links between resilience and food security. Second, we analyse also publications which assess this relation empirically. This helps to obtain an overview of existing models and, more importantly, how these models have been used in field applications, which provides useful insights in guiding policy and investment decisions (Béné et al. 2015a; Constas et al. 2016).
We pursue these objectives by focusing on the micro food system, where food is secured from three possible channels: direct entitlement (a household produces its own food entirely), indirect entitlement (a household purchases its food entirely), or mixed entitlement (a household partly produces and partly purchases food). We acknowledge, but do not focus on the macro food system, which assumes a much broader perspective beyond individual households and views the provision of food from an aggregated perspective at regional, national, transnational or global levels. At household level, shocks may affect food availability and eventually lead to food insecurity. Food security refers to the state where a household has access to sufficient, healthy and nutritious food that could sustainably nourish household members always (Pinstrup-Andersen 2009). Food security can be measured by proxies such as food consumption scores, months of adequate food provision, household food expenditure, among others (Carletto et al. 2013). A shock is an event which may disrupt the normal functions of socioeconomic agents and/or their activities, impose challenges and threaten household food security. In the literature, two types of shocks often discussed are covariate shocks affecting many individuals at the same time (e.g., poor rainfall that leads to drought, or floods) and idiosyncratic shocks (e.g., diseases/illnesses or death that affect individuals or single households). Households may use various mechanisms such as crop diversification (Lin 2011; Bullock et al. 2017), contract farming, vertical and horizontal integration and agricultural intensification (Azumah et al. 2017; Ellis 1998) to cope with these shocks and adapt (Pingali et al. 2005). The extent and success of households to employ such mechanisms for dealing with these shocks in their food systems is a measure of resilience. A resilient food system therefore retains its core functions of ensuring food security even when challenged by shocks.

The rest of the paper is organized as follows. In section 2, a brief outline of the literature search process is given, while section 3 reports and discusses the literature search outcomes. We then present a synthesis of the literature review on resilience and food security in section 4 and section 5 concludes the paper.

\section{Literature search strategy and selection of included primary studies}

To achieve the research objectives, we conducted a systematic literature search (Jesson et al. 2011; Gough et al. 2012) through CAB Abstracts, Web of Science, Scopus and Econlit, complemented with a 'snowball' in-document reference selection (i.e., identifying relevant articles referenced in other published papers). We used search terms developed from three main keywords, which are resilience (i.e., independent / intervention variable), food security (i.e., dependent variable) and household (i.e., scope variable or unit of 
analysis). These three keywords were identified with synonyms derived from the literature (see Table 1 below). We combined these three keywords into a complete search term string, connected with the Boolean operators "OR" for synonyms of the same keyword, and "AND" for the different keywords. This string was then entered into selected databases to retrieve the data.

We conducted the literature search on title, abstract and key words, and evaluated the completeness of the search strategy by checking the references from the relevant documents retrieved. We further restricted the retrieved articles by disciplinary focus, including economics, social science interdisciplinary (e.g. economics and sociology), agricultural economics and policy, and agriculture multidisciplinary. We preferred databases that provided links to export retrieved documents to the endnote reference software and excluded databases that do not relate to our subject area (e.g. psychology, ecology, etc.) and those that do not focus on primary studies (e.g. online blog, newspapers). Because most of the articles retrieved had global context, we further reduced the search results with the Boolean operator 'NOT' and the word 'global', excluding all studies with a global or macro focus.

After collecting papers from the databases, a first screening process involved reading through the titles, abstract and keywords to judge whether they related to the objective of this study. The objective was to investigate studies that addressed resilience and food security at the household level, either as the main or sub-objective of the study. Papers that did not meet the criteria were excluded outright while those that satisfied the criteria remained for further analysis. Table 1 presents the results from the initial search and further screening processes.
After the initial screening and removing duplicates, 52 studies were retained, which were further subjected to a second level but stricter screening process according to specific inclusion criteria. An included study had (1) either conceptualized and/or measured resilience and (2) the unit of study being the household. Besides these two necessary conditions, the interest also centered on studies that had (3) derived a quantitative measure of resilience and/or (4) linked resilience to food security analytically or empirically. A paper must necessarily satisfy the first two conditions to be retained for further analysis. From the retrieved documents, we also identified three more studies that were relevant to the review, and so were included. In the end, 28 studies remained for the review on the conceptual, methodological and empirical analysis of resilience and food security. For the review of the empirical evidence, we focused specifically on studies that establish a (causal or correlational) relationship between food security (or any of its proxies) and resilience (or its attributes) at the household level. In Table 2 below, we report the included studies summarizing the nature of the paper (either conceptual, analytical or empirical), the main attributes of resilience assessed by each study, data requirements and methods used for quantifying the selected resilience attributes.

\section{Conceptualization, methodological approaches and empirical evidence of resilience in food security context}

Of the selected 28 studies, 4 are purely conceptual, 16 are mainly empirical, 3 are both conceptual and analytical, 3 are

Table 1 Literature search results and screened articles

\begin{tabular}{|c|c|c|c|c|c|}
\hline \multirow[t]{2}{*}{ Search scope } & \multicolumn{5}{|l|}{ Database } \\
\hline & $\begin{array}{l}\text { Web of } \\
\text { Science }\end{array}$ & Scopus & $\begin{array}{l}\text { Cab } \\
\text { Abstract }\end{array}$ & EconLit & Total \\
\hline $\begin{array}{l}\text { Keyword 1: resilience } \\
\text { Synonyms: absorptive capacity, adaptive capacity, adaptability, diversity, diversification, } \\
\text { transformative capacity, transformability }\end{array}$ & 605 & 3516 & 4699 & 1878 & \\
\hline $\begin{array}{l}\text { Keyword 2: food security } \\
\text { Synonyms: food availability, food utilization, food access, food stability, food insecurity, } \\
\text { food consumption scores, household dietary diversity, household food expenditure, } \\
\text { undernourishment, malnourished, malnutrition, inadequate food intake, undernutrition }\end{array}$ & 2992 & 25,326 & 61,642 & 4230 & \\
\hline $\begin{array}{l}\text { Keyword 3: household } \\
\text { Synonyms: micro-level, farmers, farm level, rural livelihood }\end{array}$ & 48,239 & 176,912 & 567,028 & 94,201 & \\
\hline Combined search (\#1 AND \#2 AND \#3) & 28 & 41 & 322 & 38 & 430 \\
\hline Further screening by reading through titles, abstract, keywords & 8 & 11 & 37 & 6 & 62 \\
\hline Retained after removing duplicates & & & & & 52 \\
\hline Further screening with inclusion / exclusion criteria & & & & & 25 \\
\hline Snowball "in-document" referrals & & & & & 3 \\
\hline Retained and available for final review & & & & & 28 \\
\hline
\end{tabular}

Authors 


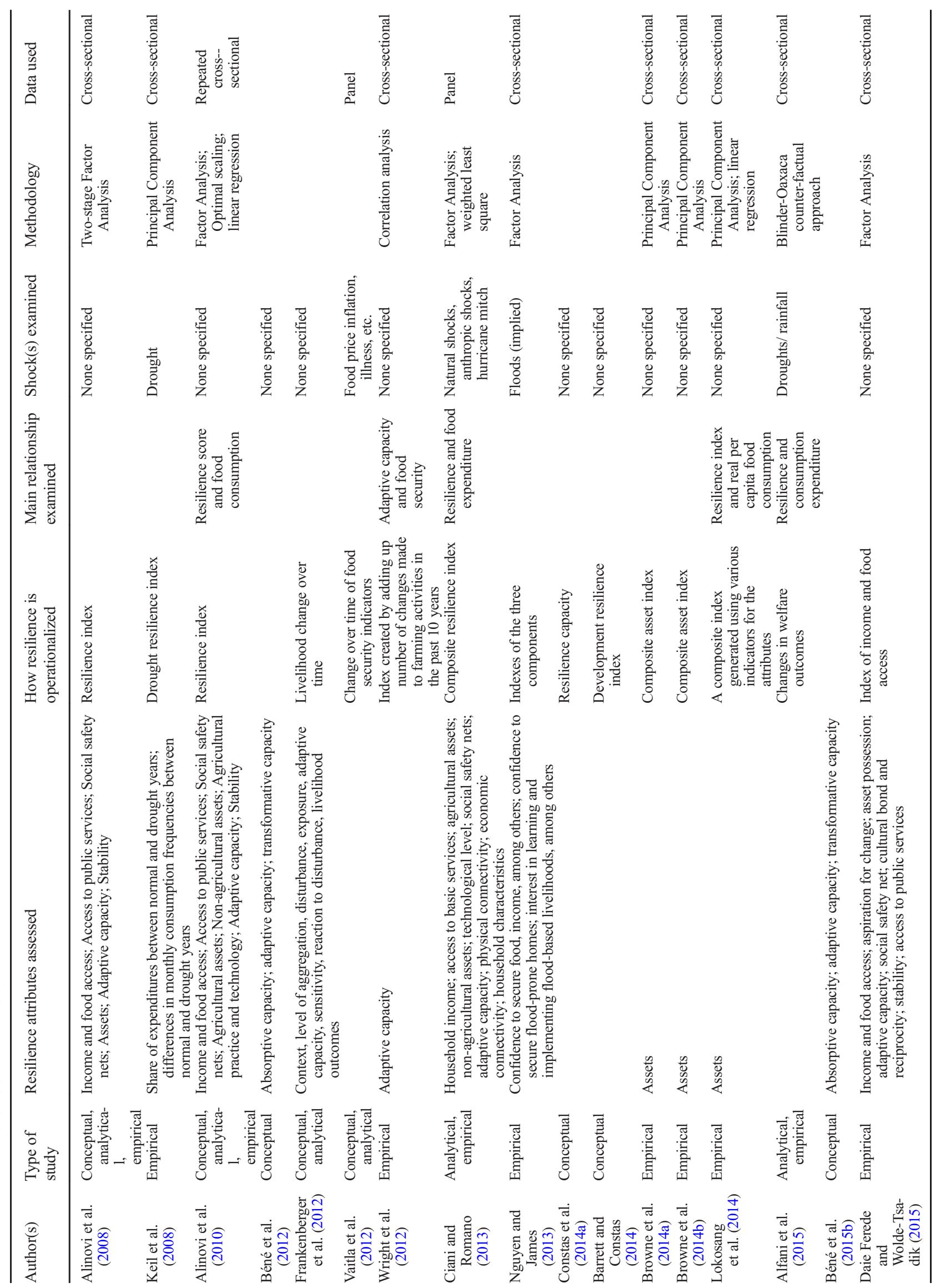




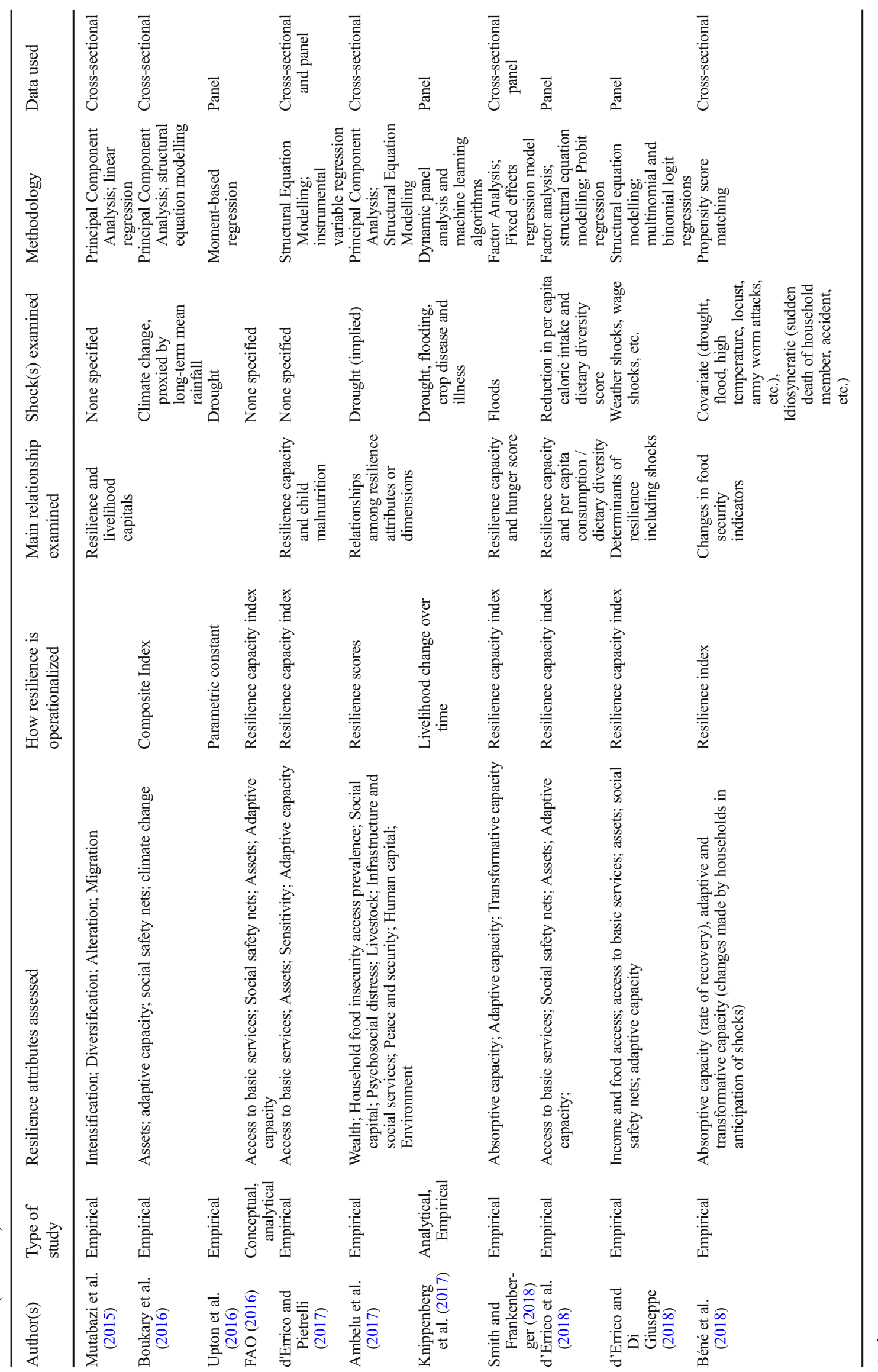


both analytical and empirical, while 2 are conceptual, analytical and empirical in scope. Of the empirical papers, only few examine the effect of resilience on some aspect of household food security. Out of the 21 studies with an empirical focus, 13 use cross-sectional data, 6 use panel data while 2 use repeated cross-sectional data for analysis. Figure 1 shows that most of the studies published before 2014 were gray literature. From 2014 onwards, the number of articles published in peerreviewed journals has increased. From the reviewed papers, the largest number of gray literature published occurred in 2012, while that published in peer-reviewed journals peaked in 2014. For many of the studies reviewed, we observe a general lack of harmony or consistency in terminologies regarding resilience and its attributes. Most of the papers based their titles on the type of shock considered. For instance, studies that examine household resilience to droughts refer to drought resilience. Besides heterogeneity in terminology, definitions of resilience in the context of household food security also showed wide variation, even though the fundamental notions conveyed by these definitions converge to the general understanding of resilience in the literature.

\subsection{Historical evolution of conceptualizing resilience from food security perspective}

The nature of resilience is such that defining and conceptualizing it from a food security perspective has been quite evasive, discerning from the historical overview that follows. Alinovi et al. $(2008,2010)$ developed a conceptual framework that was meant to link resilience and food security at the household level, with ideas for this linkage comparable to the sustainable livelihood approach of Chambers and Conway (1992), and Bebbington (1999). The conceptual models of
Alinovi et al. $(2008,2010)$ were later formalized as the FAO's RIMA-I framework (FAO 2016). Conceptually, resilience of a household is assumed to be derived from assets, capitals and opportunities (Alinovi et al. 2008, 2010). Resilience is composed of four core pillars, which are Income and Food Access (IFA), Assets (AST), Social Safety Nets (SSN) and Access to Public Services (APS). Two other dimensions, Stability (S) and Adaptive Capacity (AC), were framed to cut across these four pillars. In the 2010 study, assets were separated into Agricultural (AA) and Non-agricultural assets (NAA), while a technology uptake component was included, called Agricultural practice and technology (APT). The fundamental hypothesis was that the assets, capitals and opportunities are resilience dimensions that reflect the degree of stability (i.e., the degree to which the assets and options available to households do not change over time) and adaptability (Alinovi et al. 2008, 2010; Ambelu et al. 2017; Lokosang et al. 2014). Based on these, households with larger amounts of assets or better resources and options are perceived to be more resilient, and capable of coping/adapting better with shocks. The challenge with this resilience-food security framework, as noted by Béné et al. (2012), is the limited attention given to the agency of households to learn and adapt their systems to changing contexts. Households are not unreceptive to shocks, implying that there are both ex ante and ex post shock coping mechanisms that were not captured in the basic conceptual framework. Two other limitations of the framework are that resilience cannot be disentangled from food security, since the two variables were lumped together, and that shocks could not be distinctly analyzed because they are part of the model.

Béné et al. (2012) argued that previous conceptual models ignored the agency and power of households as decision making units. To address this limitation, they propose a 3-D
Fig. 1 Overview of gray literature and peer reviewed articles on food security and resilience published between 2008 and 2018

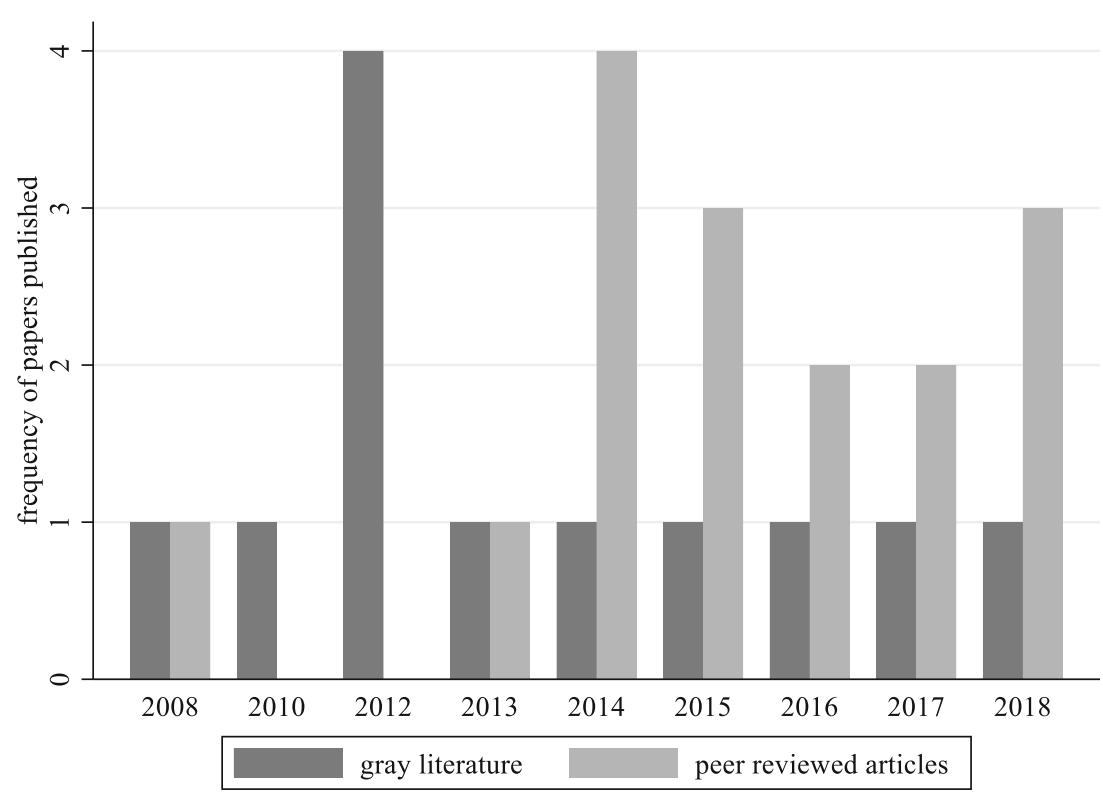


resilience framework, where resilience is understood as capacity with three key attributes which characterize the set of necessary actions that any system exposed to shocks need to undertake. The actions include: what needs to be done to help the system absorb a shock when it occurs; what needs to be done to help the system adapt in a way that makes it less exposed to the shock; and what needs to be done for the system to transform so that it is no longer prone to similar shocks. Accordingly, the three attributes derived correspond to absorptive capacity, adaptive capacity and transformative capacity.

- Absorptive capacity defines the ability of the system to minimize its exposure to shocks, but also having the mechanisms to recover quickly when shocks actualize. This capacity ensures the persistence of system functions, and mostly constitute coping strategies such as harvesting crops early to avoid floods, taking children out of school or even delaying debt repayments (OECD 2014).

- Adaptive capacity measures "the ability to make informed choices about alternative livelihood strategies based on changing conditions" (Béné et al. 2012). Diversification of livelihood activities, use of drought resistant crop varieties, among others are some key adaptive strategies that help households to deal with shocks (Heltberg and Lund 2009).

- Transformative capacity refers to the system level conditions that are necessary for changing the basic configuration of the system to create long-term resilience. Researchers argue that the adaptive and transformative capacities are necessary for dealing with the primary sources of vulnerability (Carpenter et al. 2005; Folke et al. 2010; Béné et al. 2012). In other words, adaptive and transformative capacities involve medium to longterm mechanisms that help vulnerable systems to develop robustness against specific kinds of shocks.

Frankenberger et al. (2012) proposed a conceptual framework for resilience analysis, which integrates attributes from the livelihood approach, the disaster risk reduction and the climate change adaptation literature. This framework conceptualizes resilience as consisting of the context, level of aggregation, disturbance, exposure, adaptive capacity, sensitivity, resilience and vulnerability pathways, and livelihood outcomes (e.g., food security). The framework links resilience pathways to food security in a given context via ex-ante preparedness and prevention as well as ex-post response and recovery mechanisms. Given that the ex-ante preparedness is strong, households stand less risk of experiencing food insecurity when shocks occur. While the framework recognizes food security as an outcome variable that should stay distinct from resilience, the integration of three different approaches in addition to various household-level livelihood indicators makes the information needs for operationalizing the conceptual model rather complex and difficult to implement in practice. Vaitla et al. (2012) also developed a conceptual model of resilience in the context of food security based on a livelihood change framework. This framework links household assets and various activities and strategies to income. It proposes that the households employ their assets and combine them with their activities to generate income. Given the income so generated, the model aims to understand its distribution over consumption, savings and investment. A household that invests and saves can generate more assets and income, which ensures that shocks do not have a detrimental effect on food security (adequate food consumption). Conversely, adequate food consumption ensures good health and ability to work, leading to higher income and accumulation of assets to deal with uncertainties. Indirectly, this framework links resilience to having sufficient levels of assets and income. A defining characteristic of this framework is the accommodation of feedback effects in the system. It postulates that the distribution of income feeds back into the household's asset portfolio in future periods. Such a formulation introduces dynamics which makes it quite distinct from the linear, static livelihood change models that is often used.

In 2014, the Resilience Measurement Technical Working Group (RM-TWG) of the Food Security Information Network, drawing on lessons from earlier studies proposed a resilience framework underpinned by food security objectives (Constas et al. 2014a, b). Their proposition confirmed the conceptualization by Béné et al. (2012) that resilience is a capacity with well-defined ex ante attributes. This framework provides empirical guidance to some recent studies that assess resilience and household food security (Smith and Frankenberger 2018; d'Errico and Pietrelli 2017). The RMTWG defines resilience as "the capacity that ensures that adverse stressors and shocks do not have long-lasting adverse developmental consequences" (page 6). While this definition has a development-oriented programming motivation, Barrett and Constas (2014) suggest a more precise definition for development resilience as the "capacity over time of a person, household or other aggregate unit to avoid poverty in the face of various stressors and in the wake of myriad shocks. If and only if that capacity is and remains high over time, then the unit is resilient". The conceptualization by Barrett and Constas (2014) aims to measure the dynamics of wellbeing or other livelihood outcomes in a shock-prone context, but appears less suitable for providing a quantitative measure of resilience per se (FAO 2016). However, the paper recognizes that wellbeing dynamics is conditioned by the choices households make within the limits of constraints imposed by policies, institutions and natural conditions.

Learning from the limitations in RIMA-I, FAO (2016) updated this conceptual framework to RIMA-II, in which the agency of households is directly recognized by incorporating 
shock coping strategies, such as consumption smoothing, asset smoothing and new livelihood adoption. Food security is no longer treated as an indicator of resilience and shocks are separated from the pillars that contribute to resilience capacity. In the RIMA-II framework, resilience capacity consists of access to basic services (ABS), assets (AST), social safety nets (SSN), sensitivity (S) and adaptive capacity (AC), while food security is indicated by food expenditure and dietary diversity derived using the Simpson index.

The historical perspective provided above shows a consistent improvement in the way resilience is conceptualized in relation to food security. Initial studies did not pay much attention to agency and freedom of households, but current conceptualizations either accommodate agency or acknowledge that households are rational agents which decide and choose options for better livelihoods through ex ante risk management or ex post shock coping measures. Furthermore, the initial framework of Alinovi et al. (2008, 2010) tended to select the so-called resilience pillars (attributes) arbitrarily. With time however, there appears to be recognition that the attributes included should be distinct and focused. Consequently, many studies tend to agree with the conceptual model proposed by Béné et al. (2012) that absorptive capacity, adaptive capacity and transformative capacity are adequate representation of resilience attributes (FAO 2016; Smith and Frankenberger 2018). Moreover, we observe a paradigm shift in considering resilience as an outcome variable towards the realization that resilience is a capacity that influences livelihood outcomes such as food and nutrition security, health, among others. Consistently, studies addressing resilience from a food security perspective are building consensus on the fact that shocks need to be an integral part of the resilience framework but need to stand alone as a threat to both livelihood outcomes and resilience capacity.

\subsection{Methodological approaches used to assess resilience and household food security}

We discuss operationalization as a measurement strategy for resilience, consisting of the statistical, econometric or other approaches used to turn the latent resilience concept into a quantitative measure. Before one could adequately assess resilience and food security, it is necessary to distinguish between resilience and resilience capacity. In fact, this distinction is crucial because resilience as a concept has been very difficult to operationalize. To make a distinction between resilience and resilience capacity, we follow Béné et al. (2015a), who discuss that resilience should not be seen as an end in itself but as a short term outcome. Studies that perceive resilience not as an intermediate or short-term outcome but rather an end in itself may tend to measure resilience in terms of wellbeing indicators, such as food security. However, if resilience is seen as a means to an ultimate goal, we expect studies to evaluate resilience capacity as an intermediate outcome, which then serves as a variable that influences a final desired outcome, such as food security. Such a perspective would require that resilience is measured as a separate variable from food security. We therefore assess the analytical framework on the basis of whether resilience is measured as capacity (means to an end) or as resilience (ultimate outcome).

\subsubsection{Operationalizing and measuring resilience from a household food security context}

In operationalizing resilience from a food security perspective, few studies have emerged and these use a variety of methods to quantify resilience and/or its attributes. One of the earliest studies that developed a methodology for measuring resilience in a food security context is Alinovi et al. (2008). Their analytical framework postulates resilience as a multidimensional latent variable, consisting of six key variables, which are the pillars outlined in section 3.1. Each of the pillars is also latent but can be quantified from observed socioeconomic and institutional variables. Such a setup naturally leads to a hierarchical model, where resilience is a composite of the latent pillars. To quantify these latent variables, the authors propose the application of multivariate techniques and test this using Palestinian public perception survey data. In a follow-up study, Alinovi et al. (2010) used a combination of multivariate techniques to derive a resilience index from eight variables (see section 3.1) based on the Kenya Integrated Household Budget Survey. The methodology developed in these two studies was formalized into the so-called Resilience Index Measurement Analysis (RIMA) model (FAO 2016) by incorporating two more variables, which are climate change $(\mathrm{CC})$ and enabling institutional environment (EIE). To measure these latent pillars and resilience, factor analysis and structural equations modelling were suggested.

The RIMA methodology and its predecessors helped to understand heterogeneity in the resilience index across geographical areas and livelihood groups, but suffered from a number of flaws. First, because resilience was not conceived as a capacity, the resilience index is generated as a composite of both the determinants and outcome of resilience. This is less helpful in understanding the coping mechanisms implemented by households when faced with shocks. Also, by capturing all potential shocks in the variable 'stability' the model fails to directly assess the nature and extent of household resilience to specific shocks (Frankenberger et al. 2012). Recognizing these drawbacks, Ciani and Romano (2013) made an important technical adjustment to the RIMA model. They relax the assumption of a composite resilience and food security variable, and treat food access (a proxy for food security) as an outcome variable while resilience is an explanatory variable to food security. This way, food security was measured distinctly from resilience (which was indirectly seen as capacity). Additionally, stability (which 
denoted a composite of shocks) was modelled as an independent variable to food security. The Ciani and Romano model further made a step ahead in terms of the food security dynamics by using panel data and modelling food consumption expenditure growth rates. However, resilience dynamics per se was still not addressed by the model.

Few other studies propose different methodologies for assessing resilience in food security context. Vaitla et al. (2012) derive a measure of resilience from changes in food security outcomes or indicators over two consecutive (i.e., hunger and postharvest) seasons. This empirical strategy suffers from a similar problem of not actually quantifying resilience but instead food security, because resilience was not considered as a capacity. According to d'Errico et al. (2018), the best Vaitla and colleagues could achieve was the assessment of factors influencing wellbeing. The reason being that the approach adopted and the nature of data used (i.e. crosssectional) did not guarantee an adequate measure of resilience as capacity. A slightly different analytical framework for resilience and food security is proposed by Alfani et al. (2015). Motivating their framework on the grounds of consumption and income smoothing, the authors learn from the program evaluation literature and build their model on a counterfactual framework. A synthetic measure of resilience is obtained by comparing an estimated counterfactual food security indicator against a supposed permanent value. The approach permits the authors to categorize households in the available crosssectional data set as resilient, chronically poor and non-resilient. While the approach proposed by Alfani et al. (2015) is interesting, it also fails to deal with the dynamic nature of resilience. Moreover, the model does not derive a quantitative measure of resilience as capacity.

The updated RIMA-II model treats resilience as capacity; food security and shocks are modelled as separate variables from resilience capacity (FAO 2016). Food security is considered as the 'achievement of resilience', and is no longer used as an indicator of resilience as it used to be in RIMA-I. The RIMA-II model consists of direct (descriptive) and indirect (inferential) analytical components. The direct analysis involves quantifying resilience capacity index (RCI) and a resilience structure matrix (RSM) from four variables (ABS, AST, SSN and AC) using factor analysis. The indirect analysis involves exploring the potential determinants of food security, with RCI as a key variable, through a multiple indicator multiple cause (MIMIC) framework. Despite the recognition of resilience as capacity in the RIMA-II model, limitations still exist. First the model is still not able to measure the actual dynamics of resilience and food security (d'Errico et al. 2018). Furthermore, it is not yet understood which resilience capacities are acquired or deployed in the short-, medium- and long-term horizons (FAO 2016). Additionally, the agency of farm households exhibited through ex ante management and ex post shock coping mechanisms are not yet modelled. Since resilience is dynamic, and many of the common shocks faced by farm households recur, the literature on coping and adaptation strategies suggest that farm households are not passive agents, but rather take definite or specific actions before, during and after occurrence of shocks (Levine et al. 2011).

In a number of recent studies some of the aforementioned limitations of the RIMA-II model are addressed. d'Errico et al. (2018) adopt the RIMA-II model, using the structural equations modelling to quantify resilience, but a regression analysis to examine the link between resilience capacity and food security. Through the use of a panel data, the authors account for resilience dynamics, incorporating specific shocks in the food security-resilience model. In essence, the extension by d'Errico et al. (2018) also marks an improvement in the RIMA-II analytical model. A recent paper by Knippenberg et al. (2017) develops a different analytical framework for assessing resilience in relation to food security. The model is underpinned by the theory of poverty dynamics, where food security in period $t$ depends on the value in period $t-1$, and is proxied by Coping Strategy Index (CSI). The distribution of the CSI is conditional on shocks, given a set of other characteristics that also conditions the shocks experienced by the household. Then, an autoregressive process for CSI is specified which accommodates square terms to account for nonlinearities in the persistence of CSI. While the approach is interesting, exploring resilience through the CSI reduces resilience only to the first dimension (absorptive capacity) as discussed by Béné et al. (2012), and ignores the adaptive and transformative components of resilience. Finally, Béné et al. (2018), following the approach of Béné et al. (2016), derive a resilience index based on self-evaluated questions relating to the rate of recovery from shocks based on data from the Scaling-Up Resilience to Climate Extremes for over 1 Million People in the Niger River Basin (SUR1M) project.

From the studies reviewed so far, we can discern three quantitative or statistical techniques for operationalizing and measuring resilience in relation to food security. The most widely employed approaches are multivariate methods. The second approach is less prevalent, and is based on direct proxy variables while the third is based on econometric approaches. The data used for household level resilience measurement is predominantly cross-sectional obtained from national demographic and household surveys (Boukary et al. 2016; Browne et al. 2014b). However, individual researcher-designed and self-administered surveys have also been used (Keil et al. 2008; Daie Ferede and Wolde-Tsadik 2015). The dominance of cross-sectional studies is attributed to the current lack of well-designed panel surveys that incorporate resilience concepts. Nonetheless, a few studies exist that use panel data (Smith and Frankenberger 2018; Knippenberg et al. 2017) from livelihood-centered projects. In fact, Knippenberg et al. (2017) use a high frequency (monthly) panel data specifically designed to assess resilience under the Measuring Indicators 
for Resilience Analysis (MIRA) project in Malawi. In terms of measured variables, observed indicator variables chosen for quantifying resilience tend to be arbitrary since there is no generally agreed guideline or theory for the selection of variables. Therefore, variable selection tends to be driven by context-specific and data availability factors rather than theory (Constas et al. 2016).

The multivariate techniques are index-based methods where resilience is treated as a latent variable and measured from a set of observed variables supposed to relate to resilience (capacity). The observed indicator variables may be quantitatively scaled into a composite index, with variables weighted subjectively or statistically. For the subjective weighting, the criteria vary but are often based on the literature or a Delphi technique (Alshehri et al. 2015). The common multivariate techniques include factor analysis (FA), principal component analysis (PCA), and structural equation modelling (SEM). Nowadays, the use of multiple indicator multiple cause (MIMIC) models under the SEM framework has been advocated and applied (FAO 2016; d'Errico et al. 2018). Unlike PCA which ignores measurement errors, FA takes errors into account since the set of observed variables may be an imperfect measure of the latent resilience capacity construct. SEM combines factor analysis and a regression component, where resilience or its attributes are first derived from a set of indicators, and then correlations among the measured attributes and/or other observed variables are examined using the regression component. A number of studies employ multivariate techniques in measuring resilience capacity in food security (Alinovi et al. 2008; Smith and Frankenberger 2018; d'Errico and Di Giuseppe 2018; d'Errico et al. 2018). Browne et al. (2014a) also use PCA to generate a resilience score from multiple asset indicators, arguing from the assets and risk management literature that, a measure of asset ownership could be an indicator of household resilience.

Regression-based approaches for quantifying household resilience in food security context are few. So far, only three econometric methods are encountered in the review. In the first approach, Knippenberg et al. (2017) measures resilience in two ways. First, they use an autoregressive linear probability estimator to calculate the probabilities of transitioning from one state of shock to another using a high frequency panel data from the MIRA project. With this approach, resilience is measured in terms of the perceived persistence of or recovery from a previous shock's effects by the households. Secondly, the authors employ the Blundell-Bond estimator to track how household food security (using CSI as proxy) changes over time. Here, resilient households are those that experience declining levels of the coping strategy index over time.

The second econometric approach is a moment-based estimation of development resilience by Cissé and Barrett (2016) based on a theory proposed by Barrett and Constas (2014). The moment-based method has also been applied by Upton et al. (2016) to derive a new quantitative measure of food security. The technique involves estimating both the mean (first moment) and variance (second moment) of a welfare function which accommodates lags to account for persistence in the impact of previous welfare level on its current values. The moment-based approach does not only require the availability of panel data, but also determining a threshold level of the outcome variable. Given that adequate panel data exists, this approach has the advantage that one could combine individual measures of resilience to provide a more aggregated measure. The third is a counterfactual model used by Alfani et al. (2015) and Béné et al. (2018) that is based on an intertemporal consumption or program evaluation framework. Save these few studies, the majority of the econometric approaches are used to examine the (causal) relationship between resilience and food security or some other livelihood outcomes, such as income and assets.

\subsubsection{Methods to assess causality between resilience and household food security}

To establish a (causal) relationship between resilience and household food security, various econometric methods have been employed. While many of the approaches achieve their intended aims, most do not offer causal explanation of the resulting parameters, since they do not control for endogeneity. There are two potential sources of endogeneity. The first arises from possible interdependence among the resilience attributes. Béné et al. (2012) indicate that each of the three capacities is required at specific intensity of a shock, arguing that absorptive capacity is needed or applied at low intensities (mild shocks), while adaptive capacity is important to deal with more intense (moderate) shocks. When the intensity of the shock is beyond the system's coping and adaptation, then transformative capacity is necessary to change the system configuration, making it no longer vulnerable to that specific type of shock. Nonetheless, these three capacities could reinforce each other, thereby creating interdependence. The second source of endogeneity arises from a possible reverse causal relationship among resilience capacity, shocks and food security, because the "state of being food insecure is both a cause and consequence of cycles of vulnerability" (Misselhorn and Hendriks 2017). Households with higher resilience capacity to deal with food insecurity shocks are more likely to have better and more stable food security system than households with lower resilience capacity. But it also remains possible that the more food secure is a household, the better able they are in adopting strategies or instituting mechanisms that foster their resilience to food insecurity shocks. Further, there are actions that households engage in that may expose them to shocks. Therefore, not all shocks may be exogenous to the household. 
Typically, the methods used include linear (ordinary least squares and instrumental variable) regression analysis (Alinovi et al. 2008; d'Errico and Pietrelli 2017) or its variants, such as (variance) weighted least squares (Ciani and Romano 2013), probit models (d'Errico et al. 2018), fixed effects regression models (Smith and Frankenberger 2018) and propensity score matching (Béné et al. 2016) as well as correlation analysis (Wright et al. 2012). Analysts that use ordinary least squares and probit regression analysis presuppose that resilience is exogenous to food security. Whereas this could hold in some cases, endogeneity may exist. The chance is even greater when most of the indicator variables for quantifying resilience are endogenous to household food security. Recognizing potential endogeneity issues, some studies apply instrumental variable regression (d'Errico and Pietrelli 2017) or propensity score matching (Béné et al. 2016). In the resilience and food security literature, the encountered causes of endogeneity include measurement error and selection bias. Simultaneity is not yet tested, even though Smith and Frankenberger (2018) acknowledge that there could be possible reverse causal relation between food security and shock exposure. The challenge with the propensity score matching as a way to control for endogeneity is the inability to control for unobserved heterogeneity.

Analysts that use panel data methods intend to account for resilience dynamics (d'Errico and Di Giuseppe 2018). Of course, resilience is important only in the incidence of shocks. Therefore, some authors try to examine how resilience evolves over time (given that panel data is available), and usually evaluate resilience and household food security before and after a major shock event. To examine this dynamic relationship, the difference-in-difference regression method is used, especially to examine how development project interventions enhance the resilience of households to deal with specific shocks. The aim is to provide policy advice on whether resilience-building interventions are worth their investment or not.

\subsection{Empirical evidence on the relationship between resilience and household food security}

After having discussed the methods for assessing causality/ correlation between resilience and food security in section 3.2.2, we now turn to discuss the empirical findings in the reviewed studies. Existing studies tend to use different food security measures as well as resilience attributes. This makes it difficult to employ a typical meta-analytic approach in analyzing the evidence. Due to this difficulty, we adopt a conventional approach where we try to document and discuss evidence for the various studies, with the aim to draw lessons that can guide future research and policy decisions. In order to judge whether these empirical studies adequately assess resilience and food security, we use a framework with three main criteria. The first criterion is based on the definition used for resilience.
Constas et al. (2016) already observed that people deal with resilience in different ways and came up with a classification of various definitions used: (1) "resilience is a capacity, hence can be predicted, explained or constructed by selecting other variables"; (2) "resilience, once constructed as a variable, can be defined as a capacity that predicts wellbeing"; (3) "resilience is a property, (i.e., observed change over time or return time) of a wellbeing outcome" and (4) "resilience is used as an approach strategy, to frame problems and/or structure policy interventions". We adopt this typology of definitions in order to assess which of the definitions guided the empirical analysis. Our second criterion is whether studies model the dynamic elements of resilience capacity. With the third criterion, we expect empirical studies to model shocks.

We find three sets of empirical studies. In the first set, researchers usually adopt the first definition of Constas et al. typology, hence they do not measure resilience as capacity, but rather as an indicator of food security. Resilience is therefore measured from a set of variables that relate to food security. Because they are not able to separate resilience and food security, they often neither account for resilience dynamics, nor shocks. These studies generally conclude that households with higher resilience scores have better food security, hence policies and program interventions could aim at improving food security directly, and this could lead to better resilience. We consider these studies as not adequately analyzing resilience and food security, leading to a risk of circular reasoning, particularly for the relatively recent studies in this category. Empirical studies in this category include Alinovi et al. (2008), (2010), Ambelu et al. (2017), Boukary et al. (2016), Browne et al. (2014a, b) and Lokosang et al. (2014).

In the second set of studies, researchers adopt the first and second definitions of the Constas et al. typology, hence resilience is measured as capacity and used as an intermediate variable that can predict or explain food security (d'Errico et al. 2018; d'Errico and Pietrelli 2017; Smith and Frankenberger 2018). This set of studies do better at assessing resilience and food security because they provide a quantitative measure of resilience; some of them assess resilience dynamics (d'Errico and Di Giuseppe 2018) and/or directly model shocks (d'Errico et al. 2018; Béné et al. 2016). The general conclusion from this set of studies informs resilience programming to focus on interventions that improve resilience. Once resilience is improved, food security would be assured.

In the third set of empirical studies, researchers adopt the third definition of the Constas et al. typology, such that resilience is measured as an observed change in food security over time or return time of food security to its previous level after a shock. However, studies that measure return time do not actually question whether the previous level of food security was desirable or not, which could be a major limitation. The nature of this approach is such that dynamics are often well modelled, and some incorporate shocks. Nevertheless, this 
empirical approach does not provide a quantitative measure for resilience capacity per se. Inferring from these studies, the function of policy is to provide targeted interventions that enable vulnerable households to cope with shocks so that changes in food security do not fall below catastrophic levels. Studies falling into this category include Knippenberg et al. (2017), Alfani et al. (2015), Béné et al. (2016) and Upton et al. (2016). To organize the discussion of the limited empirical evidence, the next subsections discuss findings based on the indicators of food security used.

\subsubsection{Resilience and child malnutrition, hunger score and self-reported months of adequate food}

Findings from the empirical studies indicate that resilience capacity enhances the ability of households to cope with various shocks so that household food security is not adversely affected. d'Errico and Pietrelli (2017) find that households with higher resilience capacity had lower probability of having malnourished children as well as lower number of malnourished children. Smith and Frankenberger (2018) find that Bangladeshi households with higher resilience capacity reported more months of adequate food provision or less selfreported days of hunger. Likewise, using weight-for-age as a measure of child malnutrition, Alfani et al. (2015) report that resilient households tend to have lower incidences of child malnutrition, compared to the non-resilient and chronically poor. In addition, the authors identify resilient households as those that have smaller families, better education, low dependency ratios and higher levels of quality items. Wright et al. (2012) used a proxy for adaptive capacity developed from the number of changes made in farming practices over the past 10 years by Bangladeshi households. The authors confirm a statistically strong, negative association between adaptive capacity and number of self-reported months of hunger. This result suggests that as households make more changes to their farming practices, they become more adaptable and the number of months they experienced hunger declined. Even though the authors caution against a causal interpretation of this finding, the result establishes a link between resilience (measured in terms of adaptive capacity) and food security.

\subsubsection{Food consumption, food expenditure and dietary diversity}

Available evidence indicates a positive and statistically significant relationship between food consumption, food expenditure or dietary diversity and household resilience. Alinovi et al. (2010) find that a unit increase in the level of resilience is associated with a statistically significant increase of $0.38 \%$ in the level of food consumption, controlling for location, gender and household size. Ciani and Romano (2013) establish a positive relationship between expenditure growth rate and resilience. They interpret this to mean that households with higher initial levels of resilience experience better levels of food security in future when challenged by eventualities. Lokosang et al. (2014) examine how resilience affects per capita food consumption and find statistically significant positive correlation between household resilience and real per capita food consumption in South Sudan after establishing resilience profiles across locations and population groups. Alfani et al. (2015) find that resilient households often have higher and stable consumption than the non-resilient and chronically poor. d'Errico et al. (2018) find that households with higher resilience capacities in an initial period are less likely to suffer a reduction in per capita calorie intake in a future period even when shocks hit them. On the other hand, high resilience capacity increases the probability of recovery from food loss due to shocks in previous periods. Additionally, the authors interact resilience and shocks, reporting an inverse relationship which suggests that resilience weakens the impacts of shocks on food security.

\subsubsection{Resilience as a measure of food security}

In this category of studies, resilience is measured as an indicator of food security, such that higher resilience scores are assumed to be indicative of better food security status. Since these studies do not really disentangle resilience and food security, care should be taken in interpreting their conclusions. Alinovi et al. (2008) use factor analysis to construct resilience indices for five sub-regions of Palestine. Using several observed indicators, the authors quantify household resilience to food insecurity based on Palestinian Public Perception Survey dataset. Browne et al. (2014b) create a resilience index based on asset ownership and propose this as a tool for measuring and monitoring household food security, whereas Daie Ferede and Wolde-Tsadik (2015) use income and a food access indicator derived from factor analysis as a proxy for resilience. Upton et al. (2016) first discuss the insufficiency of existing food security measures to accommodate all the components of food security proposed by 1996 FAO definition. Therefore, to bridge this measurement gap the authors propose four main axioms, which relate to scale, time, access and outcomes, and then apply a moment-based approach to reconstruct a new measure for food security. They find that development resilience measured from the moment-based model gives an adequate measure of food security that satisfies all the four axioms.

\section{Synthesis of reviewed literature and a conceptual framework for food system resilience analysis}

The Béné et al. (2012) framework provides a simplified and good starting point for operationalizing resilience from the food 
system or food security perspective. We extend this framework to focus specifically on household food security and examine the various causal pathways through which resilience capacity affects food security. Essentially, our conceptual framework considers the household unit as the agent of the food system, interacting in complex ways with the activities, and food security is an indicator of the ultimate outcome of these interactions (Ericksen 2008). We argue that households are the major decision-making units of the household food system, and the choices they make govern the overall food security of the household (Constas et al. 2016; FAO 2016).

Figure 2 recognizes absorptive capacity, adaptive capacity and transformative capacity as the three key attributes of resilience (Béné et al. 2012). These capacities relate to the decisions, choices and actions that the households embark on, either ex ante or ex post a shock. These capacities indicate how the household moderates or deals with the impact of shocks on livelihood outcomes. Our primary interest lies in how these attributes, jointly or autonomously affect household food security in the wake of shocks, through primary causal pathways. We consider these primary causal pathways as the strategies available to the households for building resilience capacity. These causal pathways therefore define the set of capabilities households have for building resilience in their food systems.
In Fig. 2, resilience capacity is developed or achieved through the primary causal pathways. Policy interventions and programmes that target livelihood or welfare outcomes could influence the resilience building strategies, hence resilience capacity (Vaitla et al. 2012; Béné et al. 2017). The economic, legal and political settings within which a household operates could influence the resilience-building strategies. The quantitative and qualitative amounts of these causal pathway variables in turn determine the extent to which shocks affect household food security. Therefore, the effect of resilience capacity on food security is accomplished through the causal pathways, which has received limited attention in the literature. The primary tangible causal pathways or resilience-building strategies that we focus on are income/savings, assets/capitals (human, financial, natural, social and physical) and production/efficiency. Intangible components of resilience-building mechanisms include risk attitudes/perceptions, self-esteem and self-efficacy or tenacity that may increase or undermine (e.g., faith or fatalism) resilience capacity. Shocks have direct influence on these intermediate variables as well as on food security. On the other hand, a drop in food security could also generate specific idiosyncratic shocks (e.g., illness can arise from poor nutrition). This makes it necessary to explore possible two-way causality among shocks, resilience capacities and food security measures, which is also a major weakness in the literature. In fact, research shows that lack of income and poverty are

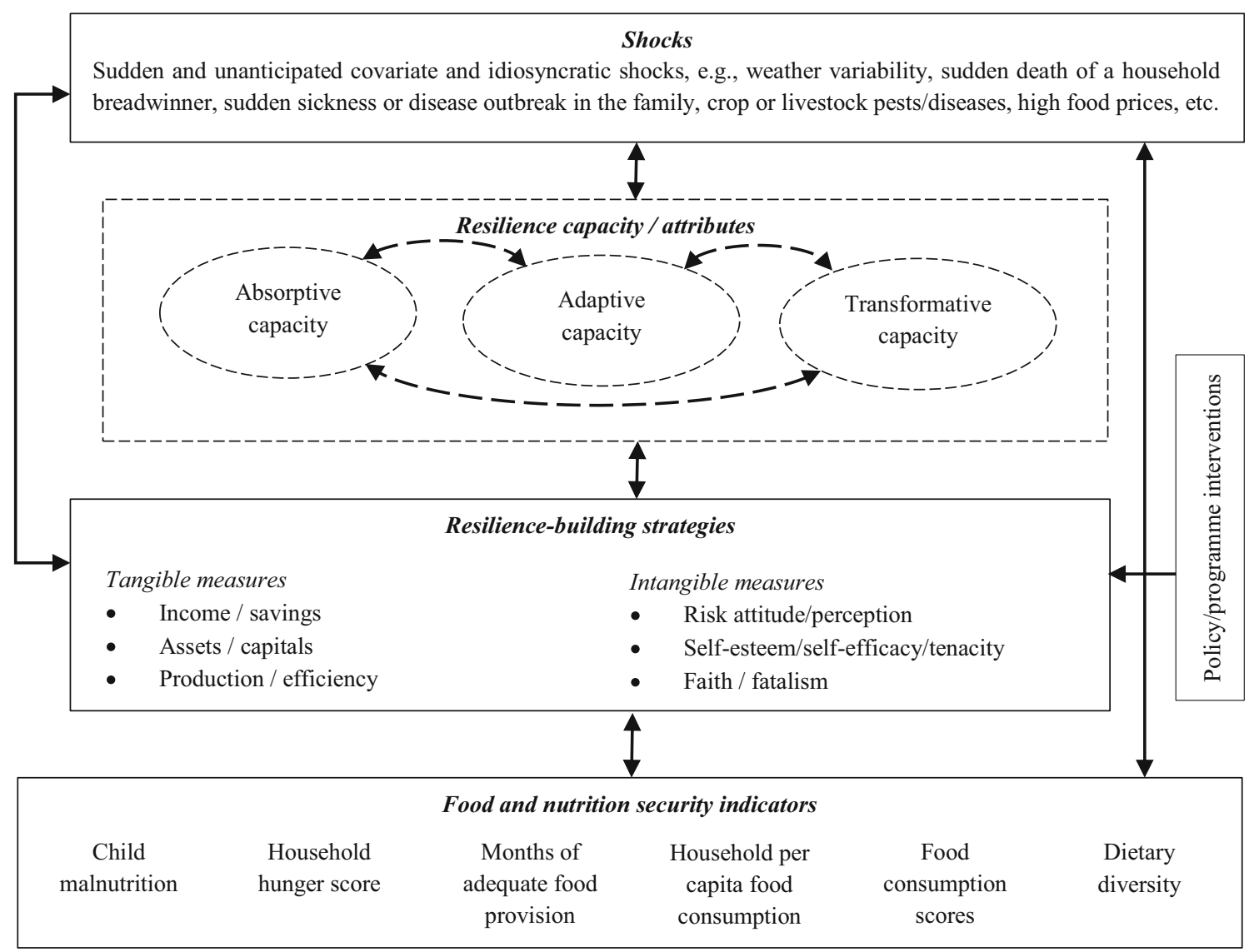

Fig. 2 Conceptual framework for the links between resilience and household food security. Source: Modified based on Béné et al. (2012) 
the fundamental causes of food insecurity (Misselhorn and Hendriks 2017). Hence, for two households with similar income levels, the one with a stable source of income could be more resilient than the other whose income source is unstable.

In the farm household setting, an important pathway for building resilience capacity to food insecurity drives through productivity and efficiency (Keil et al. 2008). A household with an efficient production system, for instance through the adoption of better agronomic practices, diversification, agroecological management or sustainable intensification, is likely to be more resilient and able to withstand shocks that threaten food security. World Bank (2008) reports that climate change affects virtually all dimensions of food security, especially availability through low productivity. For example, droughts often negatively affect crop productivity through inadequate supply of water to the plants. However, a household with an efficient production system would better manage the drought, enhance production efficiency (Keil et al. 2008) and make adequate food readily available to the household. With stable food production there could also be improved farm income if the household participates in markets. This mechanism, whereby efficiency and productivity gains generate higher resilience capacity, could lead to reduced poverty and improved food security. Efficiency gains could also come from reduced cost of managing risks and asset decapitalization (World Bank 2008), such that households do not sell out productive assets just to cope with sudden shocks.

Additionally, resilience capacity could be developed through asset accumulation and capital formation. These channels of building resilience capacity have received relatively good attention (Smith and Frankenberger 2018; Lokosang et al. 2014; Browne et al. 2014a). From the reviewed literature, many of the studies use assets and capitals as the observed indicators for indexing resilience capacity. A household with more assets is likely to be more resilient to shocks that threaten food security through consumption smoothing (i.e., selling assets to maintain current level of consumption). On the other hand, households with more capital can always leverage on these to mitigate or minimize the effects of shocks that threaten their food security. For example, a household with abundant family labor (human capital) could deploy some to engage in off-farm or non-farm work to generate extra income (Kochar 1999), whereas those with high social capital can fall on networks for assistance during stressful periods (d'Errico et al. 2018). We therefore consider these pathways as the basic blocks to building resilience capacity.

Furthermore, all these tangible components of building resilience are influenced by intangible components. People's ability to take risks, their self-efficacy and tenacity as well as their faith condition their entrepreneurial mindset or agency. Many poor farmers in traditional and rural societies remain poor and food insecure due to their risk-averse behavior, and their entrenched faith in their "gods". For instance, Keister (2011) examines how religion conditions attitude towards work, which then affects wealth (asset) accumulation. Faith and fear of the unknown (i.e., fatalism) can affect people's choices of enterprises, such that those with entrenched faith reject higher return options that they perceive as infringing upon their faith. Also, research has established that risk-averse smallholder farmers are usually reluctant to adopt improved agricultural innovations that offer higher returns, thereby remaining stuck to their known lower-return traditional methods of farming (Brick and Visser 2015). Therefore, these intangible components of resilience-building mechanisms influence the tangible components and food security outcomes.

The framework could help appreciate how policy interventions affect resilience or its attributes (Béné et al. 2017; Unmesh and Das 2017) through the primary causal pathways. The setup of the framework also permits us to examine whether the resilience attributes are endogenous by testing for simultaneity or reverse causality and self-selectivity bias. As noted by Constas et al. (2016), analyzing resilience as capacity makes it imperative to test for endogeneity. For example, a system with high absorptive capacity would have the basic capability to engage in better adaptation; but it is also possible that households with higher adaptive capacity could easily absorb the effect of mild shocks when they occur. Thus, conceptually and empirically it may not be sufficient to focus on one capacity and ignore others due to potential interdependence among the capacities. We suggest that the intervening causal variables (which represent the mechanisms for building resilience) are key, and policy interventions meant to enhance resilience could be more effective when they target these variables. Therefore, more research is needed that focuses on the causal variables and how these eventually affect food security.

\section{Conclusions}

Analyses of resilience in many disciplines show a very heterogeneous understanding of what they intend to measure which challenges scientific progress. Many studies claim to measure resilience although their analyses barely explicitly operationalize resilience. We review how these studies conceptualize and measure resilience in the context of food security. We systematically collect and review studies of that focus, by assessing their evolution in conceptualization and measurement. We furthermore critically check whether these studies indeed assess resilience and food security.

We find that both conceptual frameworks and methodologies for measuring resilience in the context of food security have witnessed a clear evolution. Studies initially focused on measuring resilience as a final outcome, but more recently resilience (capacity) is understood as an intermediate or short term outcome that influences or conditions ultimate welfare outcomes such as food security. Correspondingly, the methods of analysis have 
experienced a similar evolution. Initially, resilience was measured as an indicator of food security. Currently it is measured distinctly from food security. Multivariate techniques (e.g., factor analysis, principal component analysis, structural equations modelling and multiple indicator multiple cause models) dominate as tools for quantifying resilience capacity while few regression-based approaches have also been developed. Despite these substantial progress in conceptualization and measurement, we still have a blurred understanding of which of the tangible (e.g., income, assets, savings, etc.) and intangible (e.g., self-efficacy, tenacity, risk perception, etc.) elements are the basis of resilience capacities that are actually important and under which conditions they become important.

Second, from the review of empirical evidence we conclude that resilience (capacity) has been found to improve food security (measured by various indicators) in general. The implication is that policies and program interventions that aim to enhance resilience capacity of households can contribute towards reducing child malnutrition and ensuring long-term food security among the poor in developing countries. For instance, consider a typical rural community which hitherto had no access to the regional market. An intervention building roads to connect such a village to the market offers the opportunity for farm households to participate in markets by selling marketable surpluses to earn income. Moreover, market access can provide offfarm labor opportunities to members of the household, which would improve their income. Given higher incomes from market participation and off-farm engagement, households could save towards future uncertainties. During times of shocks, these savings could provide a hedge to smoothen consumption, such that the food security of the household becomes resilient to these shocks.

Third, in relation to whether the reviewed studies indeed assess resilience and food security, we conclude that most studies fall short of expectation. Those studies often measured resilience as an indicator of food security, which makes it difficult to distinguish between the two. They also did not examine resilience dynamics and the effects of shocks. This implies that the comparability of findings of such studies can be improved by basing future research on common grounds in terms of operationalization of the concept this research aims to assess, as well as the methodological toolkit for doing so empirically. For advancing this thought, we propose a framework in this paper which is meant to help address the weaknesses of the current literature. This framework identifies the primary causal pathways to food security as resilience-building strategies. It also allows to examine possible synergies, tensions and trade-offs among absorptive capacity, adaptive capacity and transformative capacity on food security.

Acknowledgements The authors are grateful to two anonymous reviewers for several suggestions which improved earlier versions of this manuscript. Isaac Gershon Kodwo Ansah is grateful to Wageningen School of Social Sciences (WASS) for financing his PhD studies.

\section{Compliance with ethical standards}

Conflict of interest The authors declare that they have no conflict of interest.

Open Access This article is distributed under the terms of the Creative Commons Attribution 4.0 International License (http:// creativecommons.org/licenses/by/4.0/), which permits unrestricted use, distribution, and reproduction in any medium, provided you give appropriate credit to the original author(s) and the source, provide a link to the Creative Commons license, and indicate if changes were made.

\section{References}

Alfani, F., Dabalen, A., Fisker, P., and Molini, V. (2015). Can we measure resilience? A proposed method and evidence from countries in the Sahel.

Alinovi, L., Mane, E., \& Romano, D. (2008). Towards the measurement of household resilience to food insecurity: Applying a model to Palestinian household data. In Deriving Food Security Information From National Household Budget Surveys. Experiences, Achievement, Challenges (pp. 137-152). Rome: FAO.

Alinovi, L., D'errico, M., Mane, E., and Romano, D. (2010). Livelihoods strategies and household resilience to food insecurity: An empirical analysis to Kenya. In "Conference on "promoting resilience through social protection in sub-Saharan Africa", organised by the European report of development in Dakar, Senegal", pp. 28-30.

Alshehri, S. A., Rezgui, Y., \& Li, H. (2015). Disaster community resilience assessment method: A consensus-based Delphi and AHP approach. Natural Hazards, 78, 395-416.

Ambelu, A., Birhanu, Z., Tesfaye, A., Berhanu, N., Muhumuza, C., Kassahun, W., Daba, T., \& Woldemichael, K. (2017). Intervention pathways towards improving the resilience of pastoralists: A study from Borana communities, southern Ethiopia. Weather and Climate Extremes, 17, 7-16.

Azumah, S. B., Donkoh, S. A., \& Ansah, I. G. K. (2017). Contract farming and the adoption of climate change coping and adaptation strategies in the northern region of Ghana. Environment, Development and Sustainability, 19, 2275-2295.

Barrett, C. B., \& Constas, M. A. (2014). Toward a theory of resilience for international development applications. Proceedings of the National Academy of Sciences, 111, 14625-14630.

Bebbington, A. (1999). Capitals and capabilities: A framework for analyzing peasant viability, rural livelihoods and poverty. World Development, 27, 2021-2044.

Béné, C., Wood, R. G., Newsham, A., \& Davies, M. (2012). Resilience: New utopia or new tyranny? Reflection about the potentials and limits of the concept of resilience in relation to vulnerability reduction Programmes. IDS Working Papers, 2012, 1-61.

Béné, C., Frankenberger, T., and Nelson, S. (2015a). Design, monitoring and evaluation of resilience interventions: Conceptual and empirical considerations.

Béné, C., Headey, D., Haddad, L., \& von Grebmer, K. (2015b). Is resilience a useful concept in the context of food security and nutrition programmes? Some conceptual and practical considerations. Food Security, 8, 123-138.

Béné, C., Al-Hassan, R. M., Amarasinghe, O., Fong, P., Ocran, J., Onumah, E., Ratuniata, R., Tuyen, T. V., McGregor, J. A., \& Mills, D. J. (2016). Is resilience socially constructed? Empirical 
evidence from Fiji, Ghana, Sri Lanka, and Vietnam. Global Environmental Change, 38, 153-170.

Béné, C., Chowdhury, F. S., Rashid, M., Dhali, S. A., \& Jahan, F. (2017). Squaring the circle: Reconciling the need for rigor with the reality on the ground in resilience impact assessment. World Development, 97, 212-231.

Béné, C., Riba, A., and Wilson, D. (2018). Measuring changes in resilience as a result of the SUR1M project in Niger. Available online at https://www.itad.com/wp-content/uploads/2018/05/DFIDBRACED_EA3-Impact-Evaluation_Niger_Final-for-DFID.pdf. Accessed 19 June 2019.

Boukary, A. G., Diaw, A., \& Wünscher, T. (2016). Factors affecting rural households' resilience to food insecurity in Niger. Sustainability (Switzerland), 8.

Brick, K., \& Visser, M. (2015). Risk preferences, technology adoption and insurance uptake: A framed experiment. Journal of Economic Behavior \& Organization, 118, 383-396.

Browne, M., Ortmann, G. F., \& Hendriks, S. L. (2014a). Developing a resilience Indicator for food security monitoring and evaluation: Index construction and household classification for Six African countries. Agrekon, 53, 31-56.

Browne, M., Ortmann, G. F., \& Hendriks, S. L. (2014b). Household food security monitoring and evaluation using a resilience indicator: An application of categorical principal component analysis and simple sum of assets in five African countries. Agrekon, 53, 25-46.

Bullock, J. M., Dhanjal-Adams, K. L., Milne, A., Oliver, T. H., Todman, L. C., Whitmore, A. P., \& Pywell, R. F. (2017). Resilience and food security: Rethinking an ecological concept. Journal of Ecology, 105, 880-884.

Carletto, C., Zezza, A., \& Banerjee, R. (2013). Towards better measurement of household food security: Harmonizing indicators and the role of household surveys. Global Food Security, 2, 30-40.

Carpenter, S. R., Westley, F., \& Turner, M. G. (2005). Surrogates for resilience of social-ecological systems. Ecosystems, 8, 941-944.

Chambers, R., and Conway, G. (1992). "sustainable rural livelihoods: Practical concepts for the 21st century," Institute of Development Studies (UK).

Ciani, F., and Romano, D. (2013). Testing for household resilience to food insecurity: Evidence from Nicaragua. Department of Economics and Management. University of Florence. Job Market Paper available at: http://www. unifi. it/drpeps/upload/sub/CIANIJob\% 20Market\% 20Paper. pdf. Accessed 3 Feb 2019.

Cissé, J. D., \& Barrett, C. B. (2016). Estimating development resilience: A conditional moments-based approach. African Development Bank Group, Working Paper.

Constas, M., Frankenberger, T., \& Hoddinott, J. (2014a). Resilience measurement principles: Toward an agenda for measurement design. Resilience Measurement Technical Working Group, Technical Series: Food Security Information Network

Constas, M. A., Frankenberger, T., Hoddinott, J., Mock, N., Romano, D., Béné, C., and Maxwell, D. (2014b). A common analytical model for resilience measurement. Causal framework and methodological options: Resilience measurement technical working group. Technical series no. 2. Food security information network. Available at: http:// www.fsincop.net/fileadmin/user_upload/fsin/docs/resources/FSIN Paper2_WEB_1dic\%20\%28WEB\%29.pdf. Accessed 4 Dec 2016.

Constas, M., d'Errico, M., and Garbero, A. (2016). Quantitative analyses for resilience measurement. Guidance for constructing variables and exploring relationships among variables: Resilience measurement technical working group. Technical series no. 7. Food security information network. Available at: http://www.fsincop.net/fileadmin/ user upload/fsin/docs/resources/fsin technicalseries 7.pdf. Rome. Accessed 4 Feb 2019.

d'Errico, M., Romano, D., \& Pietrelli, R. (2018). Household resilience to food insecurity: Evidence from Tanzania and Uganda. Food Security, 10, 1033-1054.
Daie Ferede, G., \& Wolde-Tsadik, M. (2015). Wild foods (plants and animals) in the green famine belt of Ethiopia: Do they contribute to household resilience to seasonal food insecurity. Forest Ecosystems, 2 (24 December 2015)-(24 December 2015).

d'Errico, M., \& Di Giuseppe, S. (2018). Resilience mobility in Uganda: A dynamic analysis. World Development, 104, 78-96.

d'Errico, M., \& Pietrelli, R. (2017). Resilience and child malnutrition in Mali. Food Security, 9, 355-370.

d'Errico, M., Grazioli, F., \& Pietrelli, R. (2018). Cross-country evidence of the relationship between resilience and the subjective perception of well-being and social inclusion: Evidence from the regions of Matam (Senegal) and the triangle of Hope (Mauritania). Journal of International Development, 30, 1339-1368.

Doran, J., \& Fingleton, B. (2016). Employment resilience in Europe and the 2008 economic crisis: Insights from micro-level data. Regional Studies, 50, 644-656.

Ellis, F. (1998). Household strategies and rural livelihood diversification. The Journal of Development Studies, 35, 1-38.

Ericksen, P. J. (2008). Conceptualizing food systems for global environmental change research. Global Environmental Change, 18, 234-245.

EU (2012). Communication from the commission to the European Parliament and the council. The EU Approach to resilience: Learning from Food Security Crises. Available at https://eur-lex. europa.eu/legal-content/EN/TXT/PDF/?uri=CELEX: 52012DC0586\&from=EN. Accessed 6 Feb 2013.

Fan, S., Pandya-Lorch, R., \& Yosef, S. (2014). "resilience for food and nutrition security," international food policy research institute (IFPRI). Washington, DC.

FAO (2016). RIMA-II: Resilience Index Measurement and Analysis II. (available at fao.org/3/a-i5665e.pdf).

Folke, C. (2006). Resilience: The emergence of a perspective for socialecological systems analyses. Global Environmental Change, 16, 253-267.

Folke, C., Carpenter, S. R., Walker, B., Scheffer, M., Chapin, T., and Rockstrom, J. (2010). Resilience thinking: Integrating resilience, adaptability and transformability.

Frankenberger, T., Langworthy, M., Spangler, T., Nelson, S., Campbell, J., \& Njoka, J. (2012). Enhancing resilience to food security shocks. White Paper (Draft). Tucson: TANGO International.

Gough, D., Oliver, S., \& Thomas, J. (2012). An introduction to systematic reviews. London: Sage Publications.

Gunderson, L. H. (2000). Ecological resilience - In theory and application. Annual Review of Ecology and Systematics, 31, 425-439.

Heltberg, R., \& Lund, N. (2009). Shocks, coping, and outcomes for Pakistan's poor: Health risks predominate. The Journal of Development Studies, 45, 889-910.

Holling, C. S. (1973). Resilience and stability of ecological systems. Annual Review of Ecology and Systematics, 4, 1-23.

Jesson, J., Matheson, L., \& Lacey, F. M. (2011). Doing your literature review: Traditional and systematic techniques. London: Sage Publications.

Keil, A., Zeller, M., Wida, A., Sanim, B., \& Birner, R. (2008). What determines farmers' resilience towards ENSO-related drought? An empirical assessment in Central Sulawesi, Indonesia. Climatic Change, 86, 291-307.

Keister, L. A. (2011). Faith and money: How religion contributes to wealth and poverty. Cambridge University Press.

Knippenberg, E., Jensen, N., and Constas, M. (2017). Resilience, Shocks and the dynamics of well-being evidence from Malawi. Available at https://pdfs.semanticscholar.org/6fac/ f0b44239fd283e98b9645c9c2127e2d46933.pdf. Accessed 11 Jan 2019.

Kochar, A. (1999). Smoothing consumption by smoothing income: Hours-of-work responses to idiosyncratic agricultural shocks in rural India. Review of Economics and Statistics, 81, 50-61.

Levine, S., Ludi, E., \& Jones, L. (2011). Rethinking support for adaptive capacity to climate change. Oxfam Policy and Practice: Climate Change and Resilience, 7, 49-97. 
Lin, B. B. (2011). Resilience in agriculture through crop diversification: Adaptive management for environmental change. BioScience, 61, 183193.

Lokosang, L. B., Ramroop, S., \& Zewotir, T. (2014). Indexing household resilience to food insecurity shocks: The case of South Sudan. Agrekon, 53, 137-159.

Martin, R., \& Sunley, P. (2014). On the notion of regional economic resilience: Conceptualization and explanation. Journal of Economic Geography, 15, 1-42.

Misselhorn, A., \& Hendriks, S. L. (2017). A systematic review of subnational food insecurity research in South Africa: Missed opportunities for policy insights. PLoS One, 12, e0182399.

Mutabazi, K. D., Amjath-Babu, T. S., \& Sieber, S. (2015). Influence of livelihood resources on adaptive strategies to enhance climatic resilience of farm households in Morogoro, Tanzania: An indicatorbased analysis. Regional Environmental Change, 15, 1259-1268.

Nguyen, K. V., \& James, H. (2013). Measuring household resilience to floods: A case study in the Vietnamese Mekong River Delta. Ecology and Society, 18 art. 13-art. 13.

OECD. (2013). Risk and resilience: From good idea to good practice. France: A scoping study for experts on risk and resilience. Organisation for Economic Cooperation and Development.

OECD. (2014). Guidelines for resilience systems analysis. France: OECD Publishing.

Pingali, P., Alinovi, L., \& Sutton, J. (2005). Food security in complex emergencies: Enhancing food system resilience. Disasters, 29, S5-S24.

Pinstrup-Andersen, P. (2009). Food security: Definition and measurement. Food Security, 1, 5-7.

Serfilippi, E., \& Ramnath, G. (2018). Resilience measurement and conceptual frameworks: A review of the literature. Annals of Public and Cooperative Economics, 89, 645-664.

Smith, L. C., \& Frankenberger, T. R. (2018). Does resilience capacity reduce the negative impact of shocks on household food security? Evidence from the 2014 floods in northern Bangladesh. World Development, 102, 358-376.

Tendall, D. M., Joerin, J., Kopainsky, B., Edwards, P., Shreck, A., Le, Q. B., Kruetli, P., Grant, M., \& Six, J. (2015). Food system resilience: Defining the concept. Global Food Security, 6, 17-23.

Thompson, J., \& Scoones, I. (2009). Addressing the dynamics of Agrifood systems: An emerging agenda for social science research. Environmental Science \& Policy, 12, 386-397.

Toth, A., Rendall, S., \& Reitsma, F. (2016). Resilient food systems: A qualitative tool for measuring food resilience. Urban Ecosystem, 19, 19-43.

UNDP. (2012). Towards a food secure future: Empowered lives, resilient nations. United Nations Development Programme: African Human Development Report.

Unmesh, P., \& Das, P. K. (2017). Do development interventions confer adaptive capacity? Insights from rural India. World Development.

Upton, J. B., Cissé, J. D., \& Barrett, C. B. (2016). Food security as resilience: Reconciling definition and measurement. Agricultural Economics, 47, 135-147.

Vaitla, B., Tesfay, G., Rounseville, M., \& Maxwell, D. (2012). Resilience and livelihoods change in Tigray, Ethiopia. Somerville: Tufts University, Feinstein International Center.

Walker, B., Holling, C. S., Carpenter, S., \& Kinzig, A. (2004). Resilience, adaptability and transformability in social-ecological systems. Ecology and Society, 9.

World Bank (2008). World Development Report 2008: Agriculture for Development. Available at http://siteresources.worldbank.org/ INTWDRS/Resources/477365-1327599046334/WDR_00_book. pdf. Washington DC. Accessed 25 Feb 2019.

Wright, H., Kristjanson, P., \& Bhatta, G. D. (2012). Understanding adaptive capacity: Sustainable livelihoods and food security in coastal Bangladesh. In CCAFS working paper. Frederiksberg: Climate change agriculture and food security.

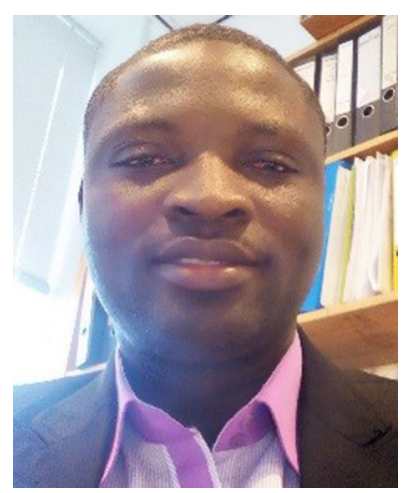

Isaac Gershon Kodwo Ansah is a lecturer at the Department of Agricultural and Resource Economics, UDS. He holds a master degree from Wageningen University and Research (Netherlands), and is currently studying for his $\mathrm{PhD}$ in the same institution. Isaac worked as a research assistant and intern, respectively, with Crops Research Institute and Forestry Research Institute of Ghana, prior to his position as a lecturer in the university. His research interests involve agricultural and applied economics, and econometric studies that have agricultural and food policy implications. Specifically, Isaac's interest borders on the nexus among shocks, coping/adaptation responses, resilience and food security in developing countries.

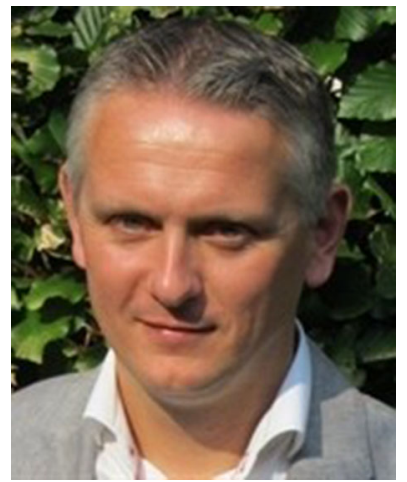

Cornelis Gardebroek is an associate professor in the Agricultural Economics and Rural Policy group at Wageningen University, The Netherlands. He received his $\mathrm{PhD}$ in Agricultural Economics at Wageningen University in 2001. His research and teaching focus on applied econometric analysis of agricultural and rural problems. He has published on issues related to risk and uncertainty, adoption of innovations, microfinance, and agricultural markets. He is currently an editorial board member of the European Review of Agricultural Economics and the Agricultural and Resource Economics Review.

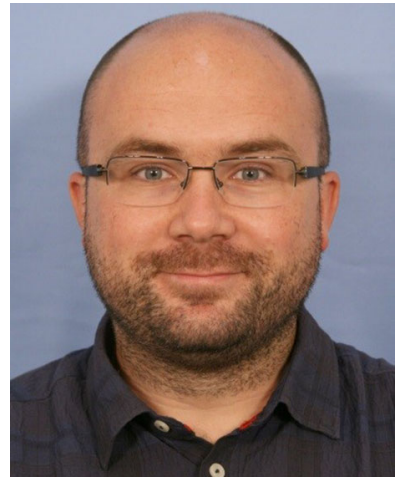

Rico Ihle is Assistant Professor at the Agricultural Economics and Rural Policy group of Wageningen University, The Netherlands. $\mathrm{He}$ holds a $\mathrm{PhD}$ in agricultural economics from Georg-August-Universität Göttingen, Germany. His research interests include the analysis of agricultural prices, economic aspects of violent political conflict, the evaluation of the effects of public policies on food and the analysis of food markets in the Middle East and Sub-Saharan Africa. 